\title{
ADAPTING LABORATORY SESSIONS IN ENGINEERING EDUCATION TO A GROWING NUMBER OF STUDENTS
}

\author{
S. Verslype, J. Peuteman, J. Boydens, D. Pissoort \\ KU Leuven, M-Group, Bruges Campus (BELGIUM)
}

\begin{abstract}
The engineering educational program at $\mathrm{KU}$ Leuven, Bruges Campus, Belgium, contains both a general scientific and a technical formation including laboratory courses. Among these laboratory courses is a laboratory course on analogue and digital electronics. Since a number of years, the teaching staff faces an increasing number of students in combination with a decreasing number of staff members for guiding these laboratory sessions. This evolution created challenges in providing the same amount of laboratory exercises while maintaining both the desired learning outcomes as well as the quality. To address these challenges, a new laboratory organization including an appropriate assessment methodology has been introduced and tested. The measures taken and presented in this paper embrace different aspects, but with a focus on teacher-independent laboratory implementation. Laboratory instructional videos have been made to guide students on the use of specific laboratory equipment. To optimize the use of student-staff interaction time during the laboratory sessions, a decent preparation by the students is mandatory. This is stimulated by providing instructional videos, information, guidelines, preparatory questions and a discussion forum hosted on a Learning Management System (LMS). During the actual experiments, the students measure physical quantities on a Printed Circuit Board (PCB) to track down the behavior of electronic circuits and components. Students are introduced and directed to the use of an electronic laboratory notebook. In this notebook they write down all measurements, phenomena, behavior descriptions and conclusions at the moment they encounter them. With the help of their notebook, students perform an automated assessment immediately at the end of the laboratory session. These open-notebook assessments consist of quizzes with questions on both measurement data and insights in the measured phenomena and behavior. The quizzes are organized on the LMS, hence randomization and automatic evaluation are performed. The automatic evaluation allows for a sufficiently fast and decent feedback to the students, giving them the opportunity to adjust their study behavior. At the same time, it also significantly decreases the assessment workload for the teaching staff compared to the traditionally used methodologies with post-lab reports. This paper further discusses the evaluation of the newly used methodology by analyzing the students' results and evolution, by comparing the students' results with the traditional methods and by surveying the students. The results of the evaluation indicate very feasible student results and distributions, while showing a large satisfaction concerning the proposed methodology among students and teaching staff.
\end{abstract}

Keywords: laboratory experiment automation, laboratory preparation, educational videos, electronic notebook, electronic assessment, Learning Management System.

\section{INTRODUCTION}

KU Leuven, Bruges Campus, Belgium, has been organizing engineering education for many years in multiple specializations, such as electronics, information and communication technologies, (renewable) energy, electromechanics, polymer processing and civil engineering. The educational program is founded on a three semester general scientific and technological formation (90 ECTS). In combination with a subsequent 90 ECTS subject-specific educational program, a three years (180 ECTS) academic bachelor degree is obtained. Finally, a single master year (60 ECTS) in a chosen specialization is organized [1]. This means that all students, starting the educational program, study the same courses in the first three semesters. Thereafter, they choose a specialization and the entire student group is split into smaller groups where each group is focusing on a chosen specialization with specific courses.

Due to the nature of the educational topic, the educational program consists of theory lectures, exercise sessions and laboratory sessions [1]. Laboratory sessions account for one quarter of the program. In the first three semesters, the laboratory sessions mostly follow a cookbook methodology: students need to perform an experiment by performing explicitly described steps. During these laboratory sessions, measurement data are collected. These data are not processed during the 
laboratory session, but afterwards at home. In fact, students usually have a couple of days or weeks to process the measurements, analyse the results and write conclusions. The results are then included in a written report and turned in for evaluation. To be able to perform the laboratory experiment in a decent way, students need to make a laboratory preparation, which is evaluated during the laboratory session by one of the laboratory assistants. From the point of view of a student, every laboratory session consists of three phases: a pre-lab preparation phase, a measurement or experiment phase and finally the post-lab processing and reporting phase.

When performing the laboratory exercises, students need to use and get familiar with dedicated laboratory equipment, like measurement devices. They also need to perform experiments based on their theoretical background obtained during the theory lectures. Hence, a good (personal) instruction and supervision of the laboratory sessions is necessary. This can be obtained by maintaining a small number of students per laboratory session supervised by an appropriate number of laboratory assistants. For many years, this has been the case in the educational program at the campus. However, due to a recent increase in the number of students starting the engineering program at the campus, student group sizes for the laboratory sessions have doubled. At the same time, the number of laboratory assistants has decreased. This evolution created challenges in providing the same amount of laboratory exercises while maintaining the desired learning outcomes and quality.

Concerning the laboratory sessions, which will be the case study of this paper, one teacher is assigned for groups of 30 students during three hours. This means that on average the teacher only has 6 minutes per student to verify the students' preparation, to verify the experiment setup, to aid the student with the measurement tools, to address problems, etc. Also the evaluation process becomes very time consuming when considering large amounts of students submitting reports for every laboratory experiment. Not only the assessment of the reporting but also evaluating the skills and competencies (research mentality, problem solving skills, interpersonal skills, etc.) used during the laboratory sessions becomes nearly impossible due to the absence of time for the teacher to observe students individually on these learning outcomes.

To address these challenges, a new laboratory organization and assessment methodology was introduced and tested in a laboratory course with multiple sessions devoted to general analogue and digital electronics. This paper discusses the new methodology and the findings considering assessment results, students' experience and teachers' experience.

\section{LABORATORY APPROACH}

To keep the laboratory sessions manageable for the students and teaching staff when considering a growing numbers of students, students should be able to perform the laboratory experiments in a teacher-independent way as much as possible. Teacher-independent ways of learning are already introduced considering distance learning [2], [3] but can, in the present context, also be useful for realizing real-life laboratory experiments. In that way students will be able to perform the experiments autonomously, hence avoiding to be queued waiting for the teachers' help. This leads to a reduced workload for the teacher when considering general help needed during the experiments, leaving more time to address specific questions and/or unforeseen circumstances during the experiment. It is also important that students, despite a large student group, have individual feedback on the performance and the results of their experiments.

As mentioned before, some measures must be taken regarding the individual assessment and the methodologies that can be used, with precision, correctness and feasibility as important factors.

The following subsections describe how the setup and the organization of the laboratory sessions are adapted to an increased student group size.

\subsection{Getting familiar with the laboratory infrastructure}

In order to perform laboratory experiments, students have to know which measurement devices are needed and how to handle them. One traditional way is giving an introductory session about the use of the measurement devices. A disadvantage of this approach is that the acquired knowledge may be partially lost when the students actually need to use a particular device during an experiment which is planned at a later time. Therefore, for the electronics laboratory, a visual recording was prepared [4] on the use of each measurement device that students will need for the experiments. In comparison with [4], for the present context, the video recordings are not only used to demonstrate the use of measurement devices and to show conclusions drawn by teaching assistants, but mainly to help and 
prepare the students for their real-life laboratory experiment. The recordings are available on the Learning Management System (LMS), implying that students can watch or replay them whenever they feel the need. In this way, students always have access to the required information, without occupying the teaching staff. Consequently, the laboratory instruction videos allow students to find and extract the information needed to use the laboratory instruments [5].

To make sure that every student understands the use of the laboratory infrastructure, a first session is provided, in which the video material is streamed for the whole class. Additionally, every student is equipped with the measurement devices and can exercise the use in a hands-on manner. During the streaming, the teacher can pause the streaming to emphasize certain aspects. After the instructional videos, the students realize some unevaluated exercises related to the measuring infrastructure so they can familiarize with the devices.

\subsection{Experiment setup}

During the considered laboratory course, it is the first time students come into contact with electronic circuits, which are the subjects of the experiments. It is important that students can focus on the actual behavior of the circuits rather than loosing precious time on assembling the circuits. Moreover, since the course is given in the general formation of the educational program, not every students (e.g. civil engineering students) need to be aware of the assembly process of electronic circuits. Consequently, every circuit is pre-assembled by the teaching staff using Printed Circuit Boards (PCB).

The PCB's are developed in such a way that students can easily make different circuit configurations. Specific measurement points are added which are easily connectable to the measurement devices implying the students don't need to measure on the components themselves. Each measurement point is labeled on the PCB and those labels are also included in the schematics of the circuits, hence they can be easily correlated to each other. By using the same labels in the accompanying laboratory assignment text, students can easily find the places where they need to measure and don't lose time in tracking down the measurement places from the text.

In the first session, students are also informed on the concept op the Printed Circuit Boards and how they need to use the boards in collaboration with the schematics and the measurement devices. They also realize a simple, unevaluated exercise on the matter.

\subsection{Laboratory preparation by the students}

Next to being prepared by a general understanding of the laboratory infrastructure, every individual laboratory experiment contains specific topics which require an appropriate understanding. Therefore, for every experiment, students need to perform a particular preparation. This preparation helps the students to perform the experiment in a feasible and correct way within the time limit. The preparation consists of answering some theoretical questions on the subject of the experiment and performing some calculations. The results of these calculations are required to realize the circuit configurations during the laboratory session. Students are also encouraged to perform simulations implying they have an idea of what can be expected from the actual measurements.

The preparation isn't assessed during the actual laboratory session. Indeed, assessing the individual preparation for all students, would induce less time to assess the students experiment itself. A choice has been made to focus on the experiment assessment. However, for each experiment an online topic is prepared in the discussion forum of the LMS where students can interact with each other and the teaching staff considering the preparation. Students who actively participate in the preparation process of the experiments are assigned one bonus point for the laboratory course. In this way, students are encouraged to actively perform the preparation and participate in the discussion.

\subsection{Performing the experiment, reporting and assessment}

During the actual experiment, students need to measure physical quantities of the electronic circuits and track down the behavior of the (sub-)circuits and components. For other laboratory courses in the educational program, students typically write down the measurement results and process them after the laboratory session. During this post-lab processing, they also try to understand the measurement results, explain the phenomena and conclude the experiment. All these conclusions are written down in a report and turned in for evaluation. As mentioned before, for large groups of students this methodology creates a large workload for the teachers concerning the assessment process. Another methodology was introduced into the electronics laboratory course. 
Instead of processing the measurement results after the laboratory session, students need to create and use an electronic laboratory notebook [6]. In this notebook students write down all measurements, phenomena, behavior descriptions and conclusions at the moment they encounter them. In this way, a chronological map of the experiment implementation is obtained. By using the communication interfaces of the measurement equipment, even screenshots and measurement data can be transferred directly from the equipment to the notebook. Although there are no requirements or guidelines concerning the setup and content of the notebook, students need to make sure they can find all relevant information concerning the experiment when needed. In fact, the notebook is as a scientific diary where a researcher notes down all his observations. To make sure the students are familiar with the concept of a laboratory and scientific notebook, an example notebook is provided considering an experiment which isn't part of the evaluated track.

The notebooks themselves are not assessed but the quality of the content of the notebook indirectly influences the experiment assessment results. This is obtained by the nature of the assessment methodology since at the end of every laboratory session an experiment quiz is provided. The results of this quiz determine the students' score for that laboratory session. During the quiz the notebook may be used implying students can look for information in their noted measurements, observations and conclusions. This means the student needs to pay attention to the following topics when making a notebook [7]:

- all measurements should be included, including measurement device configurations and/or setups;

- measurements should be accurate and precise, since there's no time to process and compare them after the laboratory session;

- determined phenomena should be described and explained, since there's no time to process the phenomena afterwards;

- the contents of the notebook should be structured in such a way that information can easily be found.

The quizzes are organized on the LMS, hence automatic evaluation is performed. This reduces the workload for the teaching staff significantly (which corresponds with experiences mentioned in [8]). The quizzes are time limited, hence forcing the students to put appropriate effort in understanding what they are doing, in supplementing their notebook and in structuring the information during the experiment. In this way, the answers to the quiz questions can be easily identified and found.

For each quiz a question pool is created, categorized into measurement questions and insight questions. The measurement questions ask for specific measurement data. Since each measurement is subject to a variance, an appropriate tolerance is used for evaluation of these questions. The insight questions assess the students on their ability to explain the phenomena they have measured. The difference with the measurement type question is that for the insight questions students need to interpret (multiple) measurements to draw a correct conclusion and obtain a correct answer to the question. Each quiz consists of 10 questions randomly picked from the question pool, but with the restriction that every student gets 5 measurement type questions and 5 insight type questions. By providing a pool which is large enough, by randomly picking questions from that pool and by randomizing the question type, content and answer possibilities (when appropriate) for each individual student, unique quiz setups are created for each student. This approach, which is quite similar with the approaches mentioned in [8], avoids fraud. Moreover, the quiz is held in the laboratory while the teaching assistant supervises the event as mentioned in [9].

The questions in the question pool arise in different forms, such as: multiple choice, multiple answer possibilities, graphically selecting correct figures and fill-in questions.

An advantage of providing the quizzes on the LMS is not only that the assessment is done automatically which decreases the teachers' workload, but, additionally and very important, the students obtain immediate feedback after performing the quiz. In this way, students immediately know the results of their quiz and hence the quality of their experiment preparation and measurements. This implies students can adapt their working methodology for the following laboratory sessions when necessary. As explained later on, there is a large satisfaction among students and teaching staff concerning the electronic assessments which corresponds with experiences in other universities [10]. 


\subsection{Individual post-laboratory student interview}

When all laboratory sessions are finished, a final session is organized per student for a limited timeslot. In this session the students' results on the individual experiments are summarized and the students' notebook of the experiment with the lowest score is considered. Here, the student has the opportunity to explain his experiment notes and conclusions. When the student is able to demonstrate his knowledge and insight on the experiment in a positive manner, the score for this experiment can be adjusted. This is an important aspect, since the preceding assessments are all performed automatically, without substantive interaction between the teacher and the student.

\section{RESULTS}

Since the described approach was new regarding the electronics laboratory course, an evaluation is needed. Indeed, before the new approach was implemented, the more traditional methodology with post-laboratory processing and reporting was used in the presented course. Hence this previous approach can be used as a reference. The evaluation of the new course approach is performed in multiple ways.

- Consider the distribution and evolution of the general scores on consecutive experiments. This allows to measure the effect of the immediate quiz feedback and the progress of the experiment and processing skills of the students.

- Since the laboratory experiment topics haven't changed in the new approach, the students results of the new approach can be compared with the results of the traditional approach.

- Survey the students themselves on the used laboratory methodology.

- Question the judgement of the teaching staff, considering the feasibility of this approach and the related workload.

The following subsections elaborate on these aspects.

\subsection{Distribution and evolution of the students' scores for the whole laboratory course}

To verify that the scores obtained by the students are distributed in a decent way, the distribution, the mean and the standard deviation are calculated for three consecutive experiments, further denoted as lab 1, lab 2 and lab 3. Fig. 1 shows the histograms of the scores of lab 1 to 3 for a population of 58 students with a score ranging from 0 to 10 . Fig. 2 shows the boxplots in the same order. This reveals that the students' scores from the automatically evaluated quizzes, are more are less normally distributed, with some deviation for lab 2.

Comparing the boxplots reveals that, as the laboratory course proceeds, there is a general increase of the marks while the scatter of the marks slightly narrows. However, since the boxplots still stay symmetrical, this indicates that the quizzes are not becoming particularly easier towards the end of the course, but that the general experimental and processing skills of the students increase throughout the course.
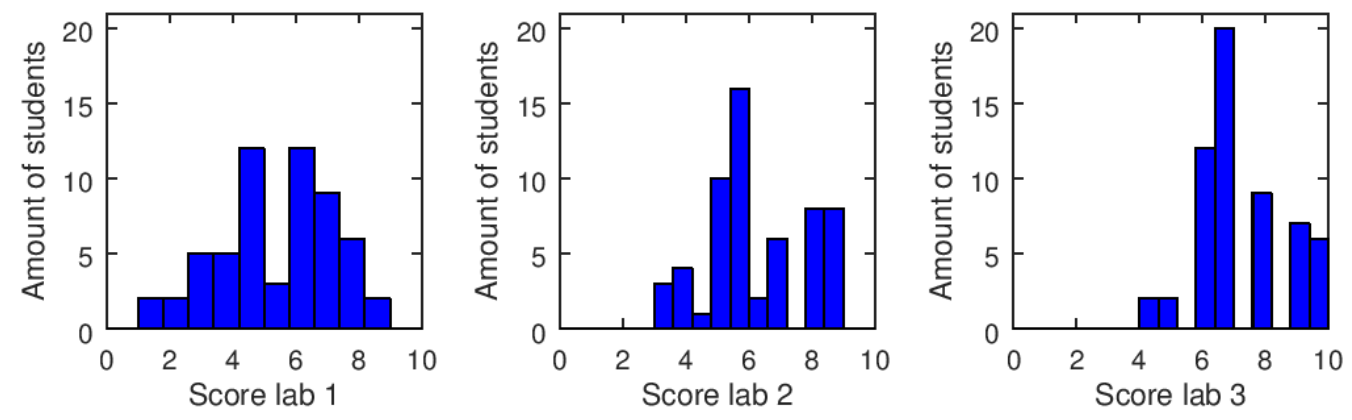

Figure 1. Histograms of lab 1 to 3 in the new approach 


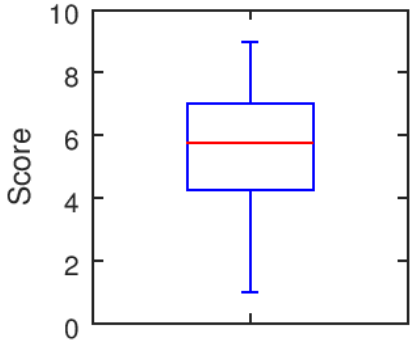

Lab 1

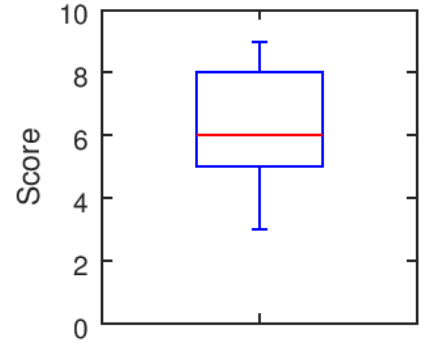

Lab 2

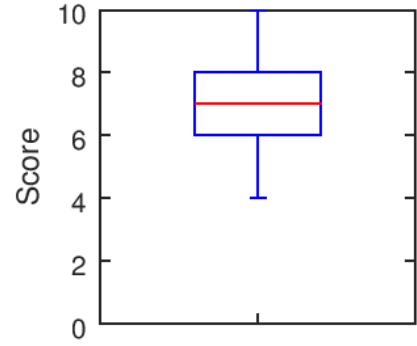

Lab 3

Figure 2. Boxplots of lab 1 to 3 in the new approach

\subsection{Comparing the students' results of the new and the traditional approach}

To verify whether the new approach has more or less the same difficulty level, knowledge evolution and skills evolution as the previous approach, the histograms and boxplots of the students' results are also made for the traditional approach. Fig. 3 and 4 show the histograms and the boxplots with regard to the same experiments. Fig. 3 and 4 are based on a dataset with a population of 79 students and also consider assessment scores from 0 to 10 . From the boxplots it can be stated that the evolution of the marks is also increasing as the course proceeds. Table 1 states the mean $\mu$ and the standard deviation $\sigma$ for the three labs in both the traditional and the new approach. Especially considering the mean values, both approaches produce similar student results.
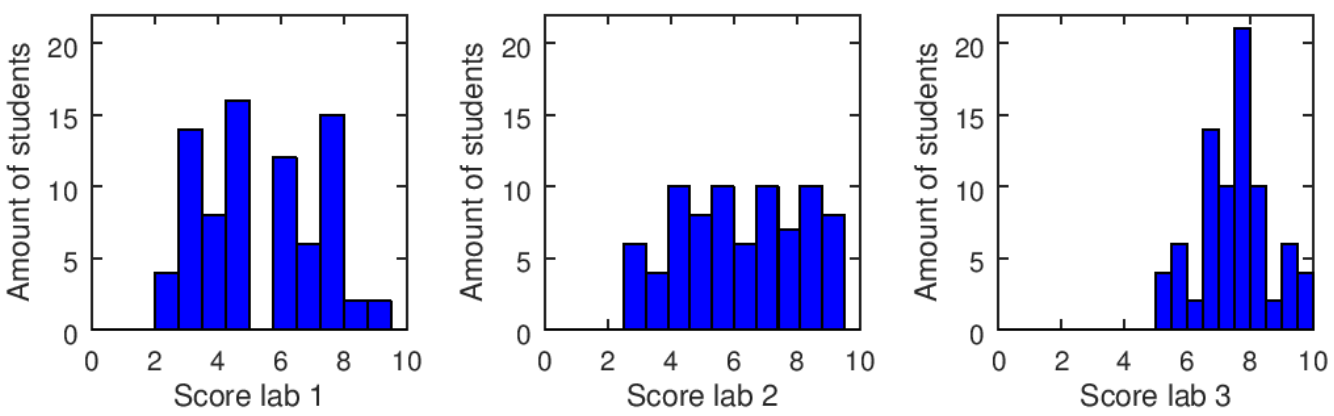

Figure 3. Histograms of lab 1 to 3 in the traditional approach

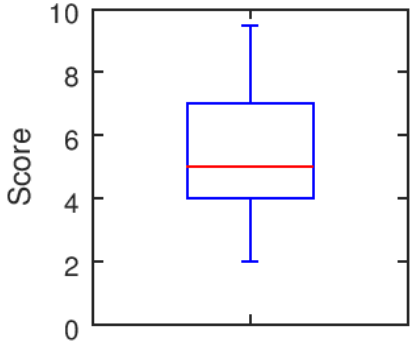

Lab 1

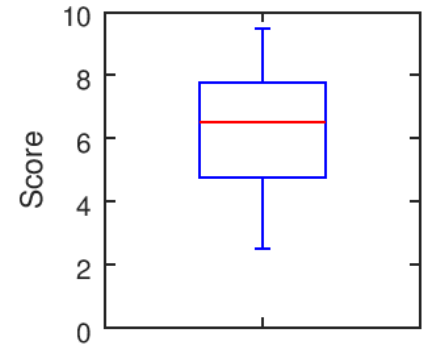

Lab 2

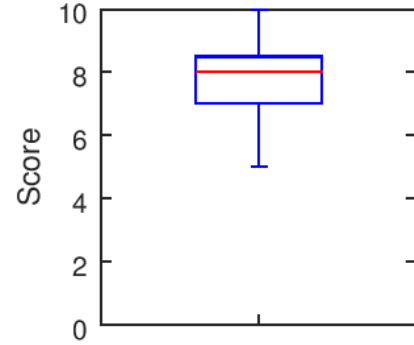

Lab 3

Figure 4. Boxplots of lab 1 to 3 in the traditional approach

\subsection{Student survey on the used laboratory approach}

It is also important to know the opinion of the students considering the introduced laboratory approach. Therefore, a survey was distributed where, based on 16 questions categorized under 5 topics, the students' feedback was asked. The 5 evaluated topics are: "Laboratory preparation", "Media and tools", "Electronic notebook vs. post-lab report", "Performing the experiment and assessment" and 
"Workload". In order to obtain an adequate dispersion of the data, a six-point Likert scale was used, ranging from "Totally disagree" to "Totally agree". The survey concluded with an open question for remarks and/or comments. From a group of 58 students who followed the laboratory course, 28 filled in the survey implying a response ratio of $48.3 \%$. The results of the survey are summarized in table 2 .

Table 1. Comparison of the means and standard deviations of the lab results in the traditional and new approach

\begin{tabular}{l|c|c|c|c}
\hline \hline & \multicolumn{2}{|c|}{ Traditional approach } & \multicolumn{2}{c}{ New approach } \\
\hline & $\mu$ & $\Sigma$ & $\mu$ & $\sigma$ \\
\hline Lab 1 & 5.44 & 1.95 & 5.41 & 1.84 \\
\hline Lab 2 & 6.21 & 1.99 & 6.30 & 1.61 \\
\hline Lab 3 & 7.72 & 1.18 & 7.33 & 1.47 \\
\hline \hline
\end{tabular}

Table 2. Results of the student survey on the laboratory approach

\begin{tabular}{|c|c|c|c|c|c|c|c|}
\hline & & $\begin{array}{c}\text { Totally } \\
\text { disagree } \\
(\%)\end{array}$ & $\begin{array}{c}\text { Disagree } \\
(\%)\end{array}$ & $\begin{array}{c}\text { Slightly } \\
\text { disagree } \\
(\%)\end{array}$ & $\begin{array}{c}\text { Slightly } \\
\text { agree } \\
(\%)\end{array}$ & $\begin{array}{c}\text { Agree } \\
(\%)\end{array}$ & $\begin{array}{c}\text { Totally } \\
\text { agree } \\
(\%)\end{array}$ \\
\hline \multirow{3}{*}{$\begin{array}{l}\text { Laboratory } \\
\text { preparation } \\
\text { (From the } \\
\text { aspect that } \\
\text { the } \\
\text { assessment } \\
\text { took place at } \\
\text { the end of } \\
\text { the session) }\end{array}$} & $\begin{array}{l}\text { I spent extra time on the } \\
\text { study of the } \\
\text { assignment. }\end{array}$ & 0 & 0 & 3.6 & 28.6 & 53.6 & 14.3 \\
\hline & $\begin{array}{l}\text { I prepared the required } \\
\text { tables etc. before the } \\
\text { session. }\end{array}$ & 0 & 0 & 10.7 & 42.9 & 35.7 & 10.7 \\
\hline & $\begin{array}{c}\text { I prepared myself better } \\
\text { in general. }\end{array}$ & 0 & 0 & 14.3 & 21.4 & 53.6 & 10.7 \\
\hline \multirow{3}{*}{$\begin{array}{l}\text { Media and } \\
\text { tools }\end{array}$} & $\begin{array}{l}\text { The online video } \\
\text { material helped me to } \\
\text { use the measurement } \\
\text { devices. }\end{array}$ & 0 & 7.1 & 3.6 & 46.4 & 39.3 & 3.6 \\
\hline & $\begin{array}{l}\text { The LMS discussion } \\
\text { boards of the course } \\
\text { are a good way to } \\
\text { discuss the laboratory } \\
\text { topics with peer } \\
\text { students. }\end{array}$ & 10.7 & 21.4 & 25 & 39.3 & 3.6 & 0 \\
\hline & $\begin{array}{l}\text { For online discussions } \\
\text { with peer students } \\
\text { considering the } \\
\text { laboratory, I prefer the } \\
\text { use of traditional social } \\
\text { media (e.g. Facebook) } \\
\text { over the LMS. }\end{array}$ & 0 & 0 & 7.1 & 10.7 & 46.4 & 35.7 \\
\hline \multirow{3}{*}{$\begin{array}{l}\text { Electronic } \\
\text { notebook vs. } \\
\text { post-lab } \\
\text { report }\end{array}$} & $\begin{array}{l}\text { A notebook is a good } \\
\text { way to process the } \\
\text { measurement results } \\
\text { and conclusions during } \\
\text { the laboratory session. }\end{array}$ & 0 & 0 & 3.6 & 17.9 & 50 & 28.6 \\
\hline & $\begin{array}{l}\text { The use of a notebook } \\
\text { helps to immediately } \\
\text { write down conclusions } \\
\text { and insights obtained } \\
\text { during the laboratory } \\
\text { session. }\end{array}$ & 0 & 0 & 14.3 & 25 & 50 & 10.7 \\
\hline & I prefer the use of a & 0 & 0 & 0 & 7.1 & 28.6 & 64.3 \\
\hline
\end{tabular}




\begin{tabular}{|c|c|c|c|c|c|c|c|}
\hline & $\begin{array}{l}\text { notebook above a post- } \\
\text { lab report. }\end{array}$ & & & & & & \\
\hline \multirow{4}{*}{$\begin{array}{l}\text { Performing } \\
\text { the } \\
\text { experiment } \\
\text { and } \\
\text { assessment }\end{array}$} & $\begin{array}{l}\text { Since the assessment } \\
\text { took place at the end of } \\
\text { the laboratory session, I } \\
\text { spent additional } \\
\text { attention on the } \\
\text { correctness and } \\
\text { accuracy of the } \\
\text { measurements. }\end{array}$ & 3.6 & 3.6 & 3.6 & 39.3 & 50 & 0 \\
\hline & $\begin{array}{l}\text { Since the assessment } \\
\text { took place at the end of } \\
\text { the laboratory session, I } \\
\text { immediately tried to } \\
\text { understand/explain the } \\
\text { measured phenomena. }\end{array}$ & 0 & 3.6 & 0 & 28.6 & 57.1 & 10.7 \\
\hline & $\begin{array}{l}\text { I am more involved in a } \\
\text { laboratory session } \\
\text { when using a notebook } \\
\text { and with an assessment } \\
\text { at the end of the } \\
\text { session, than in the } \\
\text { approach with a post- } \\
\text { lab report. }\end{array}$ & 0 & 0 & 10.7 & 39.3 & 39.3 & 10.7 \\
\hline & $\begin{array}{c}\text { By receiving the } \\
\text { assessment results at } \\
\text { the end of the } \\
\text { laboratory session, I } \\
\text { adjusted my behaviour } \\
\text { towards the next } \\
\text { sessions (i.e. } \\
\text { preparation, } \\
\text { methodology, ...). }\end{array}$ & 0 & 0 & 7.1 & 14.3 & 46.4 & 32.1 \\
\hline \multirow{3}{*}{ Workload } & $\begin{array}{l}\text { The workload for a } \\
\text { laboratory session with } \\
\text { a notebook and a quiz } \\
\text { is higher compared to } \\
\text { the approach with a } \\
\text { post-lab report. }\end{array}$ & 7.1 & 35.7 & 42.9 & 7.1 & 3.6 & 3.6 \\
\hline & $\begin{array}{l}\text { I spent the laboratory } \\
\text { hours (with notebook } \\
\text { and assessment at the } \\
\text { end of the session) } \\
\text { more efficiently, than } \\
\text { when the assessment } \\
\text { would take place at a } \\
\text { later time (i.e. with a } \\
\text { post-lab report). }\end{array}$ & 0 & 3.6 & 7.1 & 32.1 & 35.7 & 21.4 \\
\hline & $\begin{array}{l}\text { Due to the assessment } \\
\text { at the end of the } \\
\text { laboratory session, I felt } \\
\text { more stress, compared } \\
\text { to a laboratory } \\
\text { approach with } \\
\text { assessment at a later } \\
\text { time (i.e. a post-lab } \\
\text { report). }\end{array}$ & 3.6 & 0 & 28.6 & 35.7 & 25 & 7.1 \\
\hline
\end{tabular}

The questions related to "Preparation" allow to conclude that the majority of the students prepared themselves better for the laboratory experiments, because they were assessed at the end of the laboratory session. This can be explained by the fact that they don't have time after the session to 
analyse and modify their results. Indeed, because of the assessment students should adopt a firsttime-right mentality. Hence, the students need to be well prepared and informed about the experiment.

The "Media and tools" questions show that online instructional video materials can be used to teach the use of the laboratory equipment. The answers also reveal that, despite the discussion possibilities embedded in the course on the online LMS, students rather use their own, personal social media accounts on the traditional social media to discuss the experiments. The bonus for being active on the LMS discussion boards does not significantly change that behaviour. Analysis on the LMS states this observation. For a group of 58 students and 3 different experiments only 3 questions have been posted on the discussion board, with only 1 question answered by a peer student.

When asking the students about the use of a notebook as a laboratory tool, they are surely convinced of the usefulness regarding noting measurement data, observations and conclusions. When presenting the choice between the electronic notebook and the post-lab report, not a single student prefers the post-lab report over the notebook.

The survey questions on the topic "Performing the experiment and assessment" indicate that students tend to spend more attention in making sure that the measurements are correct and accurate. They also immediately draw the appropriate conclusions about the observations since the assessment directly follows the laboratory session. This is a good attitude because it means that they need to be involved with the experiment while it is running. Indeed, when asking students about their involvement in the experiments, they indicate they are more involved, than when they have time after the session to process measurements and conclusions. Another important aspect is the fact that almost all students slightly to strongly agree that obtaining immediate assessment results at the end of the sessions influences their methodology for further experiments [11].

The last topic addressed by the survey concerns the workload. The students indicate that the workload for the new approach is not larger than the workload for a laboratory with a post-lab report, although they spent more time to be prepared for the experiment. This indicates that there is a shift of workload from report writing to experiment preparation.

\subsection{Experience of the teaching staff}

A final aspect to take into account is the experience of the teaching staff. This can be divided into three different aspects.

The first aspect is the workload for the preparation of the laboratory course setup in the new approach. Here it is clear that it takes additional effort to create the video materials, the quizzes, the question pools and, for this electronic oriented laboratory course, the electronic circuits on PCB's. However the major part of this work only needs to be done once while it can be used for multiple iterations of the course.

The second aspect considers the feasibility of guiding and assisting the students during the laboratory sessions itself. The teaching staff noticed that students were better prepared for the experiments in the new approach than in the traditional approach. This implies students were less teacher dependent during the laboratory sessions, leaving more time for the teacher to address unforeseen circumstances and phenomena. This consideration was one of the main goals when introducing the new approach.

The last aspect is the assessment workload. Since the assessment evaluation is done automatically by the LMS, the assessment workload is remarkably lower compared to the traditional approach were a lot of reports needed to be read and evaluated. Because the LMS also provides the students with direct feedback on their quiz results, less workload remains for the teaching staff. Of course, the teaching staff stays available to address specific questions considering feedback. Students also benefit from this approach because getting feedback fast allows them to improve their behaviour. Giving appropriate feedback in case of a growing number of students in combination with a decreasing size of the teaching staff is also addressed in [11].

\section{CONCLUSIONS}

The new laboratory approach presented in this paper was implemented in the educational engineering program and verified for its feasibility for the students and the teaching staff. Results were analysed and compared with the traditional approach for the laboratory course. 
The new approach has feasible student scoring outputs, which are similar with the ones of the traditional approach. Also the students are in favour of the new methodology.

The setup of the new methodology implies an important one time effort for the teaching staff, but it reduces the workload when considering assessment and feedback. This means that, when organizing the laboratory course for at least two years, a significant decrease of the workload is created for the teaching staff. Meanwhile, the same technical subjects can be educated in the laboratory course in combination with a positive student feeling.

\section{REFERENCES}

[1] J. Peuteman, A. Janssens, J. Boydens, D. Pissoort, "Integrating Research and Design Oriented Skills in a Learning Trajectory for Engineering Students," in EDULEARN18 Proceedings, 2018. EDULEARN18. pp. 877 - 886, 2018.

[2] J. Boydens, J. Peuteman, A. Janssens, "Motivating Students for making Exercises in an Online Course by providing them Self-Evaluation Capabilities," in EDULEARN17 Proceedings, 2017. EDULEARN17. pp. 4984 - 4993, 2017.

[3] I. Vandecasteele, R. De Craemer, J. Peuteman, J. Poelaert, F. Priem, "LabVIEW based development of Remote Laboratory Sessions," in Proceedings of the Fourth European Conference on the Use of Modern Information and Communication Technologies, 2010. ECUMICT 2010. pp. 141 - 152, 2010.

[4] A. Degraeve, J. Peuteman, D. Pissoort, K. Armstrong, "Teaching EMC using an EMC demonstration unit," in 2018 Joint IEEE International Symposium on Electromagnetic Compatibility and 2018 IEEE Asia-Pacific Symposium on Electromagnetic Compatibility, 2018. EMC/APEMC 2018. pp. 1255 -1260, 2018.

[5] S. Suhonen, J. Tiili, "Videos in physics theory and laboratory teaching: usage and retention analytics," in Proceedings of the 45 SEFI Annual Conference 2017, 2017. SEFI 2017. pp. 1132 - 1139, 2017.

[6] M. Cardenas, "Electronic Laboratory Notebooks versus Paper Notebooks: A Comparison of Undergraduate Experimental Engineering Laboratory Submissions," in Proceedings of the 2014 American Society for Engineering Education Zone IV Conference, 2014. ASEE Zone IV 2014. pp. 96 - 107, 2014.

[7] C. Roberson, D. Lankford, "Laboratory Notebooks in the Science Classroom," in Science Teacher, vol. 77, no. 1, pp. $33-42,2010$.

[8] C. Zilles, M. West, D. Mussulman, C. Sacris, "Student and Instructor Experiences with a Computer-Based Testing Facility," in EDULEARN18 Proceedings, 2018. EDULEARN18. pp. 4441 - 4450, 2018.

[9] A. Karadeniz, R. Peytcheva-Forsyth, S. Kocdar, M.R. Okur, "Approaches to prevent cheating and plagiarism in E-learning assessment: higher education students' views," in EDULEARN18 Proceedings, 2018. EDULEARN18. pp. 5047 - 5054, 2018.

[10] R. Laurila, M. Anderson, T. Niemi, "Experiences on taking electronic exams at Tampere University of Technology," in Proceedings of the 45 th SEFI Annual Conference 2017, 2017. SEFI 2017. pp. $1243-1252,2017$.

[11] M.R. Van Diggelen and M. Funk, "Stimulating feedback conversations: design and evaluation of a feedback tool in Industrial Design Education," in Proceedings of the 43'd SEFI Annual Conference 2015, 2015. SEFI 2015. 